\title{
Mad cow update: risk now limited
}

Published at www.cmaj.ca on Sept. 27

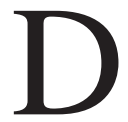
espite the sporadic discovery of new cases of bovine spongiform encephalopathy (BSE), Canadian officials say a ban on the use of ruminant material in feed and other measures are working effectively to limit the risk to humans.

So assured are experts that Canada has contained the mad cow disease threat from the national herd of 14 million cattle that they are turning their attention to other animal spongiform encephalopathies, as well as the secondary threat of variant CreutzfeldtJakob disease (vCJD) transmission between humans.

"It's theoretically possible that there's a domestic case of vCJD in the next 20 years, but [the outlook] is pretty reassuring," says Daniel Krewski, director of the R. Samuel McLaughlin Centre for Population Health Risk Assessment at the University of Ottawa in Ontario.

The latest discovery of BSE within a Canadian cow occurred in February. It was the 17th confirmed case of BSE in Canadian-born cattle. Of those, 12 were born after a ban on the use of ruminant material in feed was introduced in 1997, according to the United States Centers for Disease Control and the Canadian Food Inspection Agency. Canada had peaks of five cases in 2006 and four cases in 2008, with one in 2009 and one thus far in 2010.

But "we don't test every cow, so there may have been more," says Krewski.

While the precise cause of cases after the feed ban is unknown, "yearover-year" feed remaining in refilled silos, along with contamination of trucks, are a problem, says Dr. Brian Evans, chief veterinary officer and chief food safety officer with the Canadian Food Inspection Agency.

"An amount as small as a grain of rice could be sufficient to infect an animal," explains Evans. Research in Scotland has shown that feed up to 15 years old stuck

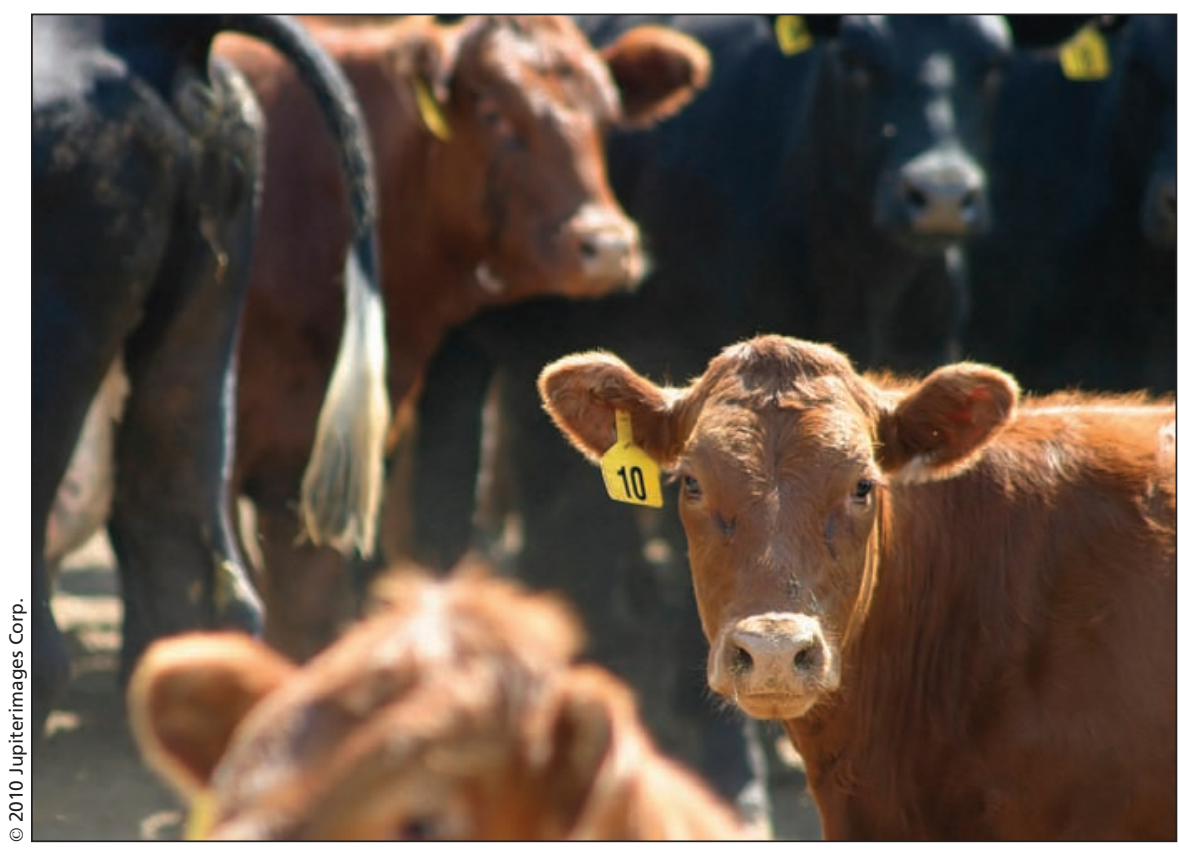

Canada had peaks of five cases of bovine spongiform encephalopathy in 2006 and four cases in 2008. There was one in 2009 and thus far, there has been one in 2010.

in seams of concrete and wood feed bunkers can mix with current feed (Vet Rec 2002; 151[15]:451-2 and Vet Rec. $2005 ; 157[24]: 782-3)$. "The impact of feed bans can take 7 to 10 years to work through the feed," he says.

Unlike Europe, in which all slaughtered cattle are tested for BSE, Canada only has a targeted surveillance program. Evans says cattle aren't tested unless they meet one of " 4 Ds: dead without a known cause, dying, diseased, or 'down' (weak, stumbling, or unable to rise)." Cattle are first screened for rabies, and those negative for rabies are then tested for BSE. Last year, more than 34000 cattle were tested.

"We do expect to find a small number of cases over the next couple of years. We will need to maintain surveillance through 2014 to assess the impact of the enhanced feed ban," says Evans.

But cases are no longer reported in press releases because the Canadian Food Inspection Agency changed its procedures for public reporting of BSE in 2009, following "engagements with consumer groups," says Evans. BSE cases are now added to tables on the agency's website, along with other reportable animal diseases such as anthrax, foot and mouth disease, scrapie, and chronic wasting disease. Press releases will be issued only if a case is "epidemiologically significant — if it was the first time for a disease in a species, or a disease thought to be eradicated," says Evans.

Most of the cattle contaminated with BSE to date have been seven to nine years of age. The neurodegenerative disease has not been detected in cattle younger than 50 months.

"The vast majority slaughtered for human consumption are 18 to 22 months of age - even if they were exposed, they would not have lived long enough to become infected," Evans says.

In 2003, the Canadian Food Inspection Agency started requiring removal of "specified risk material" from all slaughtered cattle. The decision was based on research showing that BSE concentrates in the distal ileum, as well as in the 
skull, brain, trigeminal ganglia, eyes, tonsils, spinal cord and dorsal root ganglia of cattle 30 months of age or older. Since 2007, such material from slaughtered cattle cannot be used in any animal feed, including pet food, or in fertilizer.

Attention has shifted to potential new sources of animal and human prion disease. Evans says an atypical strain of BSE has been found in older animals, while Krewski says secondary transmission of vCJD from human to human is an emerging concern, with four cases confirmed internationally.

Other animal spongiform encephalopathies are being monitored to ensure they do not infect new species, especially humans. There is an epidemic of chronic wasting disease among elk and deer, as well as other cervids, in the western US and Canada. - Carolyn Brown, Ottawa, Ont.

DOI:10.1503/cmaj.109-3678 